\author{
I. Chapman · B. Parker · S. Doran · C. Feinle-Bisset • \\ J. Wishart $\cdot$ S. Strobel $\cdot$ Y. Wang $\cdot$ C. Burns $\cdot$ C. Lush $\cdot$ \\ C. Weyer $\cdot$ M. Horowitz
}

\title{
Effect of pramlintide on satiety and food intake in obese subjects and subjects with type 2 diabetes
}

Received: 18 November 2004 / Accepted: 27 January 2005 / Published online: 21 April 2005

(C) Springer-Verlag 2005

\begin{abstract}
Aims/hypothesis: Long-term trials in insulintreated subjects with type 2 diabetes have shown that adjunctive treatment with the amylin analogue pramlintide reduces $\mathrm{HbA}_{1} \mathrm{c}$ levels and elicits weight loss. While amylin reduces food intake in rodents, pramlintide's effect on satiety and food intake in humans has not yet been assessed. Methods: In this randomised, double-blind, placebo-controlled crossover study, 11 insulin-treated men with type 2 diabetes (age $60 \pm 9$ years, BMI $28.9 \pm 4.8 \mathrm{~kg} / \mathrm{m}^{2}$ ) and 15 nondiabetic obese men (age $41 \pm 21$ years, BMI $34.4 \pm 4.5 \mathrm{~kg} / \mathrm{m}^{2}$ ) underwent two standardised meal tests. After fasting overnight, subjects received single subcutaneous injections of either pramlintide $(120 \mu \mathrm{g})$ or placebo, followed by a preload meal. After $1 \mathrm{~h}$, subjects ate an ad libitum buffet meal. Energy intake and meal duration were measured, as were hunger ratings (using visual analogue scales), and plasma cholecystokinin, glucagon-like peptide- 1 and peptide YY concentrations over time. Results: Compared with placebo, pramlintide reduced energy intake in both the type 2 diabetes $(\Delta-202 \pm 64 \mathrm{kcal},-23 \pm 8 \%, p<0.01)$ and obese $(\Delta-170 \pm 68 \mathrm{kcal},-16 \pm 6 \%, p<0.02)$ groups, without affecting meal duration. Hunger and hormonal analyte profiles provided evidence that pramlintide may exert a primary satiogenic effect, independently of other anorexigenic gut
\end{abstract}

Duality of interest. C. Weyer, Y. Wang, C. Burns, C. Lush and S. Strobel are employees of and shareholders in Amylin Pharmaceuticals (San Diego, CA, USA). I. Chapman, B. Parker, S. Doran, C. FeinleBisset, J. Wishart and M. Horowitz are employees of the Royal Adelaide Hospital.

I. Chapman · B. Parker · S. Doran · C. Feinle-Bisset · J. Wishart · M. Horowitz

Department of Medicine, Royal Adelaide Hospital, University of Adelaide,

Adelaide, South Australia, Australia

S. Strobel · Y. Wang · C. Burns · C. Lush · C. Weyer $(\bowtie)$

Amylin Pharmaceuticals,

9360 Towne Centre Drive,

San Diego, CA, 92121, USA

e-mail: christian.weyer@amylin.com

Tel: $+1-858-6427076$

Fax: $+1-858-3341076$ peptides. Conclusions/interpretation: The results indicate that enhanced satiety and reduced food intake may explain the weight loss observed in long-term pramlintide trials.

Keywords Amylin · Hunger - Obesity · Peptide hormones . Satiety

Abbreviations CNS: central nervous system - CCK: cholecystokinin - GLP-1: glucagon-like peptide-1 - ITT: intent-to-treat $\cdot$ LS: least squares · PYY: peptide YY · VAS: visual analogue scale

\section{Introduction}

In healthy subjects, food intake triggers the release of numerous pancreatic and gastrointestinal peptide hormones that play an important role in the regulation of postprandial metabolism. This regulation may include the quantity of food consumed, as well as the absorption and disposition of ingested nutrients [1-5]. Specifically, there is growing recognition that peptide hormones secreted from the gut and from pancreatic islets in response to meals may act as humoral and/or neuronal feedback signals to the central nervous system (CNS), mediating the perception of fullness and satiation during meals (thus contributing to meal termination), and/or the maintenance of satiety after meals (thus affecting inter-meal intervals) [1-5]. Whether a given peptide hormone has a physiological role in the regulation of food intake and body weight is typically established by supporting evidence from animal studies (using gain-offunction studies with the peptide itself and loss-of-function studies with selective antagonists and/or gene knock-outs) and from clinical studies assessing the effect of the peptide on satiety and food intake in humans [1-5]. To date, randomised, controlled crossover studies in humans have reported an increase in food intake at a buffet meal following the administration of the gastric hormone ghrelin [6], and a decrease following the administration of the gut hormones cholecystokinin (CCK) [7, 8], glucagon-like peptide-1 (GLP-1) [9-11], oxyntomodulin [12] and peptide YY3-36 
$[13,14]$, and the islet hormones glucagon [15], pancreatic polypeptide [16] and somatostatin [17].

Amylin is a 37-amino-acid peptide hormone that is normally co-secreted with insulin from pancreatic beta cells in response to meals [18]. Amylin acts as a neuroendocrine hormone that binds with high affinity to specific amylin receptors in the CNS, most notably the nucleus accumbens, dorsal raphe and area postrema [19-21], and exerts various glucoregulatory and anorexigenic effects [18]. Amylin complements the effects of insulin in postprandial glucose homeostasis by regulating the rate of glucose appearance in the circulation via suppression of nutrient-stimulated glucagon secretion and slowing of gastric emptying [18]. In addition, numerous non-clinical studies have provided evidence that amylin is involved in the central regulation of food intake and body weight [22-27]. Specifically, central or peripheral administration of amylin was shown to reduce food intake and body weight in rodents in a dose-dependent manner [22-25], whereas central or peripheral administration of a selective amylin antagonist increased food intake and body fat stores [26, 27].

Pramlintide, a soluble synthetic analogue of human amylin, was recently approved in the United States to be given at mealtimes as an adjunct to mealtime insulin therapy in patients with type 1 or type 2 diabetes who have failed to achieve desired glucose control, despite optimal insulin therapy with or without a concurrent sulphonylurea agent and/ or metformin respectively $[28,29]$. Also, pramlintide is currently in clinical development as a potential treatment for obesity in individuals without diabetes. Consistent with the observed glucoregulatory actions of amylin in rodents, clinical studies in insulin-treated patients with diabetes have shown that pramlintide reduces postprandial glucose excursions by suppressing glucagon secretion and slowing gastric emptying [30-32]. In long-term (6-12 months) clinical studies of insulin-treated type 1 or type 2 diabetic patients, adjunctive treatment with pramlintide lowered $\mathrm{HbA}_{1} \mathrm{clev-}$ els and produced a significant and sustained reduction in body weight, particularly in those patients who were overweight at baseline [33-36].

Based on the anorexigenic effects of amylin in rodents and the weight-lowering effect of pramlintide in patients with diabetes, we hypothesised that pramlintide would enhance satiety and decrease ad libitum food intake in humans. This hypothesis was formally tested in the present randomised, double-blind, placebo-controlled crossover study, which employed a well-established experimental buffet-meal design.

\section{Subjects and methods}

Subjects Two groups of subjects were studied: subjects with insulin-treated type 2 diabetes (14 randomised, 11 evaluable) and obese subjects without known diabetes (16 randomised, 15 evaluable). All subjects were male; females were excluded because of the confounding effect of menstrual cycle on hunger and food intake [37].
The primary inclusion criteria required that subjects were between 18 and 70 years of age, were euthyroid (thyroidstimulating hormone within the normal range), had stable weight $(<5 \%$ weight change within $2-6$ months prior to screening), and had baseline clinical laboratory tests (haematology, clinical chemistry and urinalysis) that were either normal or, if abnormal, judged to be clinically insignificant by the investigator. Subjects also had to be unrestrained eaters, as defined by a score of $<11$ on Factor 1 (cognitive restraint) of the Three-Factor Eating Questionnaire [38]. The obese non-diabetic subjects had BMIs between 30 and $40 \mathrm{~kg} / \mathrm{m}^{2}$ [39].

Subjects with insulin-treated type 2 diabetes were required to have a BMI between 20 and $40 \mathrm{~kg} / \mathrm{m}^{2}, \mathrm{HbA}_{1} \mathrm{c}$ levels between 6.5 and $10.0 \%$, a stable insulin regimen for at least 6 months prior to screening, and were to be free of severe hypoglycaemia (defined as episodes requiring intravenous glucose or glucagon) for at least 4 weeks prior to screening. Subjects with type 2 diabetes using metformin in conjunction with insulin were required to be on a stable dose of metformin for at least 3 months prior to screening $(\leq 2,000 \mathrm{mg} /$ day $)$ and were to be free of clinically relevant gastrointestinal side effects.

Subjects were excluded if they had any of the following: (1) a clinically significant history or presence of active cardiac disease; (2) untreated or poorly controlled hypertension; (3) gastrointestinal, hepatic, renal, autoimmune or haematological disease; (4) malignant disease requiring chemotherapy; (5) eating disorders such as bulimia or anorexia nervosa; or (6) an acute febrile illness within 2 weeks of screening. Subjects were also excluded if they had a history of alcohol or drug abuse, had donated blood within 30 days of screening, had received any investigational drug within 90 days of screening, or were currently being treated with systemic steroids, anti-obesity agents, antidepressants, antipsychotic drugs or drugs known to affect gastrointestinal motility.

The study was designed in accordance with the Declaration of Helsinki and was approved by the Human Ethics Committee of the Royal Adelaide Hospital. All patients provided informed consent prior to randomisation.

Study design This was a single-centre, randomised, doubleblind, placebo-controlled, two-period crossover study. Subjects were instructed to report to the clinical research unit in the morning following an overnight fast (from 22.00 hours). Each study visit was separated by at least $72 \mathrm{~h}$, and subjects were to maintain routine dietary habits between study visits. On both study days, subjects completed the same standardised meal test.

Prior to the meal test, an intravenous cannula was placed in an antecubital vein for blood sampling ( $t=-60 \mathrm{~min})$. Venous blood samples were collected over $5.5 \mathrm{~h}$, and assessments using visual analogue scales (VASs) were conducted at time points similar to those used for venous blood sample collection.

At $t=0 \mathrm{~min}$, subjects received a single s.c. injection of either $120 \mu \mathrm{g}$ of pramlintide (Amylin Pharmaceuticals, San Diego, CA, USA) or placebo, immediately followed by in- 
gestion of a standardised preload meal. A dose of $120 \mu \mathrm{g}$ was chosen because it has been widely studied in long-term trials [33-35], it has been shown to elicit a sustained reduction in body weight [33-36], and is intended for clinical use in insulin-treated subjects with type 2 diabetes. The preload meal consisted of $125 \mathrm{~g}$ of banana blended with 150 $\mathrm{ml}$ of low-fat $(2 \%)$ milk and $150 \mathrm{ml}$ of water (estimated energy content $\sim 189 \mathrm{kcal} ; 6 \mathrm{~g}$ protein, $36 \mathrm{~g}$ carbohydrate, 3 $\mathrm{g}$ fat), and was consumed within $3 \mathrm{~min}$. At $t=0 \mathrm{~min}$, subjects with type 2 diabetes also injected an appropriate dose of their usual mealtime insulin (same dose on both occasions) as determined by the investigator. For those type 2 diabetic subjects using metformin in conjunction with insulin, the usual metformin dose was omitted on the morning of the two study days.

At $t=60 \mathrm{~min}, 1 \mathrm{~h}$ later, subjects were offered an ad libitum buffet meal for a period of $45 \mathrm{~min}(t=60-105 \mathrm{~min})$. The buffet meal provided food items in quantities exceeding expected intake. Food selections included ham and chicken sandwiches prepared on white or whole-wheat bread with a variety of condiments/toppings (cheese, tomato, lettuce, cucumber and mayonnaise), and yogurt, fruit salad, individual fruits, custard, orange juice and coffee.

Measurements/endpoints Total energy and macronutrient intake was calculated using the DIET/4 program (Xyris Software, Highgate Hill, QLD, Australia) [9]. Meal duration (i.e. total duration of eating at the buffet meal) was also recorded.

Subjective ratings of hunger, fullness and nausea over the course of the meal test were repeatedly recorded using a paper-based, standardised 100-mm VAS [8, 40]. Subjects were carefully trained in the use of the VAS prior to each experiment.

Two satiety quotients were calculated as integrated measures of satiety and food intake [41]. The prandial satiety quotient, which is an indicator of suppression of hunger during a meal, normalised for energy intake at the meal, was calculated as follows: [VAS hunger rating obtained prior to the buffet $(t=1.0 \mathrm{~h})$ minus AS hunger rating obtained when the subject finished eating] divided by total energy intake at the buffet meal. The postprandial satiety quotient, which is an indicator of the return of hunger after a meal, normalised for energy intake at the meal, was calculated as follows: [VAS hunger rating obtained $5 \mathrm{~h}$ after the beginning of the buffet meal $(t=5.0 \mathrm{~h})$ minus VAS hunger rating obtained when the subject finished eating] divided by total energy intake at the buffet meal.

Blood samples were repeatedly collected for the measurement of postprandial hormonal and metabolic responses, including plasma concentrations of CCK (RIA; intra- and inter-assay precision is $\leq 9$ and $27 \%$, respectively) [42, 43], total GLP-1 (RIA; intra- and inter-assay precision is $\leq 15$ and $18 \%$, respectively), active GLP-1 (ELISA; intra- and inter-assay precision is $\leq 9$ and $13 \%$, respectively), total peptide YY (PYY) (RIA; both intra- and inter-assay precision is $\leq 9 \%$ ) [44], and triglycerides (enzyme-based assay using a Hitachi 917 Biochemical Analyzer; intra- and interassay precision is $\leq 2$ and $3 \%$, respectively). Triglyceride assays were run by Dorevitch Laboratory Services (Camberwell, VIC, Australia), whereas total and active GLP-1 and total PYY assays were run by Linco Research (St Charles, MO, USA).

Statistical analyses The evaluable population was used for all efficacy analyses, whereas the intent-to-treat (ITT) population (all randomised subjects) was used for the safety analyses. Of 30 randomised subjects (ITT), 26 comprised the evaluable population. Four subjects were excluded from the efficacy analyses: two subjects (one subject with type 2 diabetes and one obese subject) did not consume any food at the buffet meal (thus precluding the assessment of meal duration, satiety quotient, and postprandial hormone and triglyceride responses), one subject with type 2 diabetes did not consume the entire preload meal, and one subject with type 2 diabetes withdrew prematurely due to adverse events.

Total energy and macronutrient intake and meal duration were summarised descriptively according to diabetes status and treatment received. Incremental VAS hunger, fullness and nausea score profiles, and incremental CCK, GLP-1, PYY and triglyceride concentration-time profiles, were calculated by subtracting the baseline score (collected at $t=0$ min) from the score at each successive time point. The robustness of the rating results for hunger, fullness and nausea was tested by analysing the respective VAS data with and without individual outlying values. Both analyses yielded comparable results, and the data presented here do not include outlying values. Each parameter was summarised descriptively. Incremental areas under the per cent score/concentration-time curves (AUCs) from $0-1 \mathrm{~h}$ (premeal period), $1-5 \mathrm{~h}$ (peri- and post-meal period) and $0-5 \mathrm{~h}$ (entire period) were calculated using the linear trapezoidal method. The $\mathrm{AUC}_{0-1 \mathrm{~h}}$ was not calculated for triglycerides.

Data are presented as means \pm SEM. For all parameters measured, the results of the pramlintide and placebo groups were analysed using mixed-effect models that included treatment, treatment sequence and treatment period as fixed effects, and subject within sequence as a random effect. The least squares (LS) means, the LS mean differences between pramlintide and placebo, and the corresponding SEMs, the 95\% confidence intervals and $p$ values for the LS mean differences were derived from the mixed-effect models.

In addition, a correlation analysis was employed to study the relationship between total energy intake and the concomitant pre- vs post-meal change in VAS hunger ratings. The Pearson's correlation coefficients (with $p$ values) are presented. A $p$ value of less than 0.05 was considered statistically significant.

\section{Results}

\section{Baseline characteristics}

The baseline characteristics of the insulin-treated type 2 diabetic subjects and the obese non-diabetic subjects are provided in Table 1. On average, the insulin-treated type 2 diabetic subjects were older and weighed less than the obese 
Table 1 Baseline characteristics of the study population

\begin{tabular}{lcc}
\hline & $\begin{array}{c}\text { Type 2 diabetic } \\
\text { subjects }(n=11)\end{array}$ & $\begin{array}{c}\text { Obese non-diabetic } \\
\text { subjects }(n=15)\end{array}$ \\
\hline Age (years) & $60.2 \pm 8.5$ & $41 \pm 21$ \\
$\begin{array}{l}\text { Race, Caucasian/ } \\
\text { other }(\%)\end{array}$ & $100 / 0$ & $87 / 13$ \\
Weight $(\mathrm{kg})$ & $93.5 \pm 15.6$ & $108.6 \pm 22.0$ \\
Height $(\mathrm{cm})$ & $179.9 \pm 5.7$ & $177.0 \pm 8.2$ \\
$\begin{array}{l}\text { BMI }\left(\mathrm{kg} / \mathrm{m}^{2}\right) \\
\begin{array}{l}\text { Duration of } \\
\text { diabetes (years) }\end{array}\end{array}$ & $28.9 \pm 4.8$ & $34.4 \pm 4.5$ \\
$\mathrm{HbA}_{1} \mathrm{c}(\%)$ & $7.8 \pm 0.5$ & $\mathrm{NA}$ \\
\hline
\end{tabular}

Values are means $\pm \mathrm{SD}$, except for race

non-diabetic subjects. The insulin-treated type 2 diabetic subjects, of whom eight (57\%) were concomitantly treated with metformin, had a mean $\mathrm{HbA}_{1} \mathrm{c}$ level of $\sim 8 \%$, and a mean diabetes duration of $\sim 14$ years.

Food intake

In both groups, the mean total energy intake at the buffet meal was significantly lower following pramlintide than it was following placebo injection (Fig. 1a, b). In the insulinusing type 2 diabetic group, the total energy intake was 829 $\pm 72 \mathrm{kcal}(3,465 \pm 301 \mathrm{~kJ})$ following placebo and $627 \pm 75$ $\mathrm{kcal}(2,621 \pm 314 \mathrm{~kJ})$ following pramlintide injection - a reduction of $202 \pm 64 \mathrm{kcal}(844 \pm 268 \mathrm{~kJ})$ or $\sim 23 \pm 8 \%(p<0.01)$ (Fig. 1a). Of the 11 evaluable subjects with type 2 diabetes, nine $(\sim 82 \%)$ had lower total energy intake following pramlintide than following placebo injection, while two subjects had greater total energy intake (Fig. 1a inset). In the obese non-diabetic group, the total energy intake was $1,128 \pm 81$ kcal $(4,715 \pm 339 \mathrm{~kJ})$ following placebo and $958 \pm 100 \mathrm{kcal}$ $(4,004 \pm 418 \mathrm{~kJ})$ following pramlintide injection-a reduction of $170 \pm 68 \mathrm{kcal}(711 \pm 284 \mathrm{~kJ})$ or $\sim 16 \pm 6 \%(p<0.02)$ (Fig. 1b). Of the 15 obese non-diabetic subjects, $14(\sim 93 \%)$ had lower total energy intake following pramlintide than following placebo injection, while only one subject had a greater total energy intake (Fig. 1b inset).

In both groups, the reduction in mean total energy intake following pramlintide injection was attributable to proportionate reductions in energy derived from fat, carbohydrate and protein, such that the percentage macronutrient composition of the meal was unaffected by treatment (Fig. 1a, b).

The meal duration was similar following placebo and pramlintide injection in both the insulin-treated type $2 \mathrm{di}$ abetic subjects ( $25 \pm 2$ vs $25 \pm 3 \mathrm{~min}, p=0.80)$ and the obese non-diabetic subjects ( $29 \pm 2$ vs $28 \pm 3 \mathrm{~min}, p=0.70$ ).

\section{VAS ratings of hunger, fullness and nausea}

Hunger In both groups, and on both occasions, the mean incremental hunger ratings decreased slightly in response to the preload meal $(0-1 \mathrm{~h})$, decreased markedly in response to a

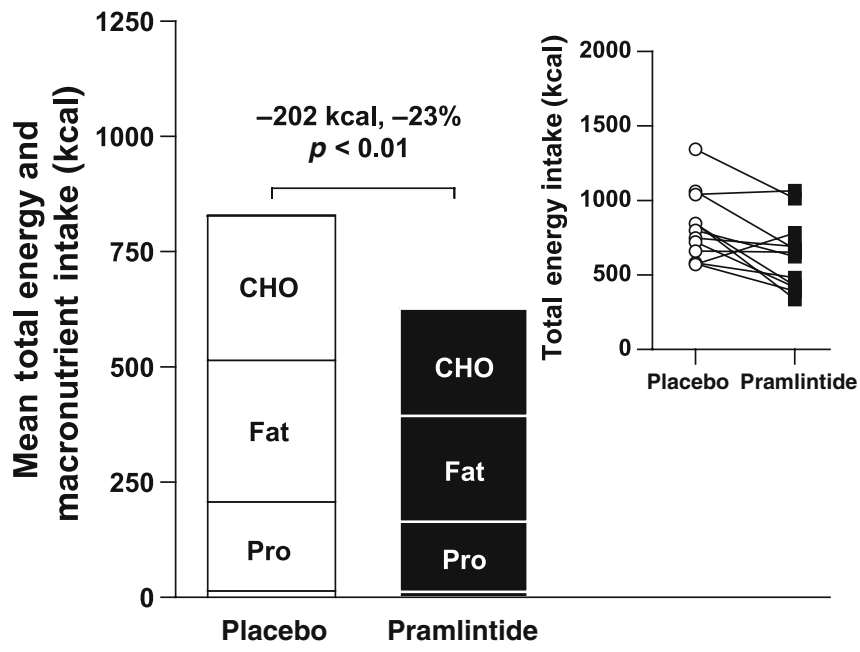

b

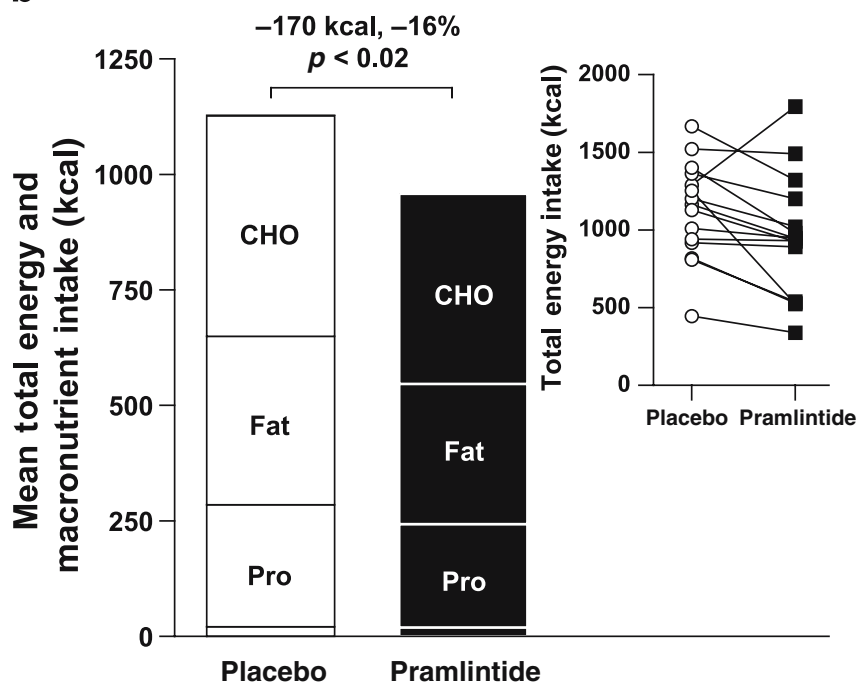

Fig. 1 Mean total energy intake (overall height of column) and macronutrient intake (height of subcolumns) at the ad libitum buffet meal following a single s.c. injection of placebo or $120 \mu \mathrm{g}$ of pramlintide in 11 subjects with insulin-treated type 2 diabetes (a) and 15 obese non-diabetic subjects (b). Insets represent individual results for total energy intake. kilocalorie to kiloJoule conversion: $1 \mathrm{kcal}=4.18$ kJ. $\mathrm{CHO}$, carbohydrate; Pro, protein

the ad libitum buffet meal (1-1.75 h), and then gradually reverted towards baseline values during the postprandial period (1.75-5 h) (Fig. 2a, b).

For both groups, the decreases in hunger ratings in response to the preload meal were comparable following placebo and pramlintide injection (Fig. 2a, b). The decreases in hunger ratings in response to the buffet meal, as well as the return of hunger ratings during the postprandial period, were comparable following placebo and pramlintide injection, both among the type 2 diabetic subjects and among the obese non-diabetic subjects, despite the fact that total energy intakes at the buffet meal were 23 and $16 \%$ lower, respectively, following pramlintide injection (Fig. 2a, b). 
a

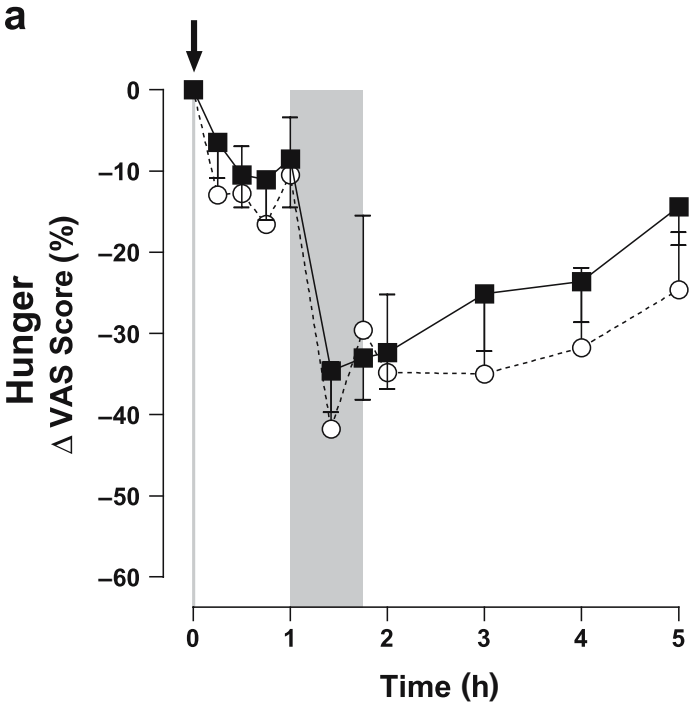

C

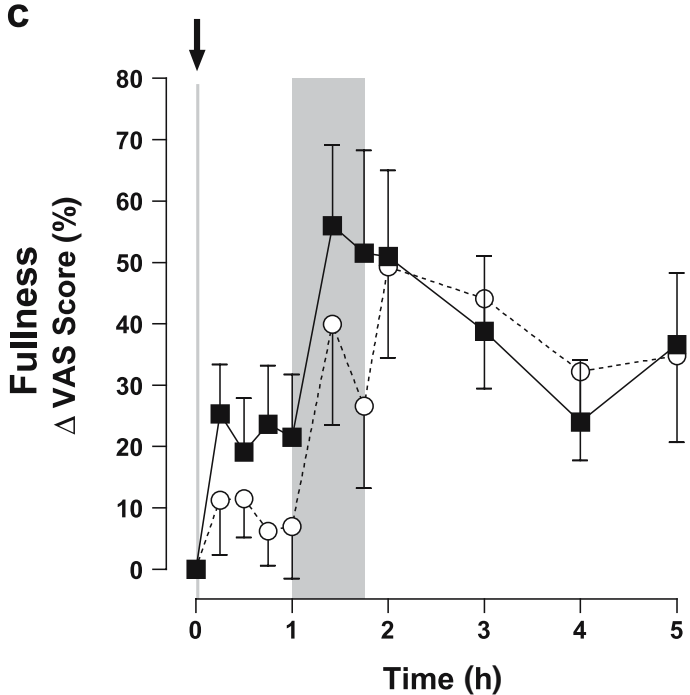

e

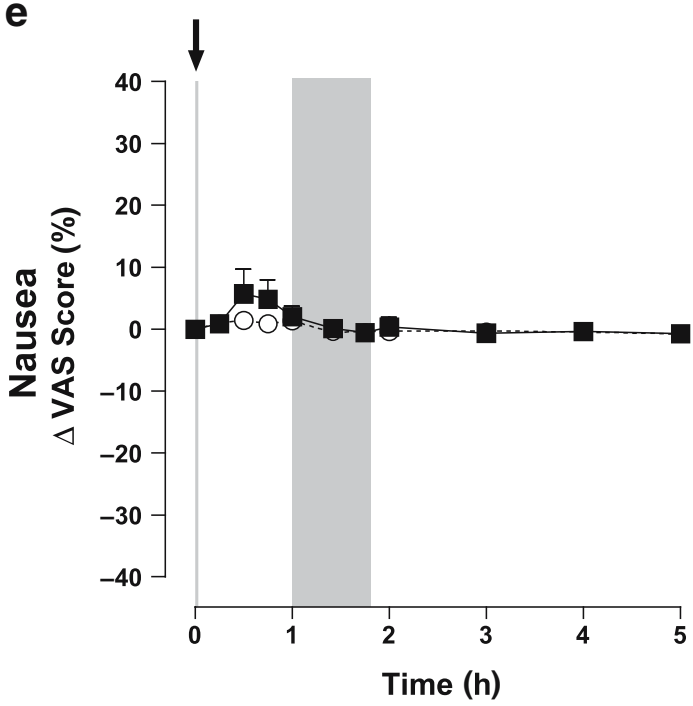

Fig. 2 Mean $( \pm$ SEM) incremental changes in VAS ratings of hunger $(\mathbf{a}, \mathbf{b})$, fullness $(\mathbf{c}, \mathbf{d})$, and nausea $(\mathbf{e}, \mathbf{f})$ following a single s.c. injection of placebo (open circles, dotted lines) or $120 \mu \mathrm{g}$ of pramlintide (filled squares, solid lines) in 11 subjects with insulin-treated type 2 diabetes b

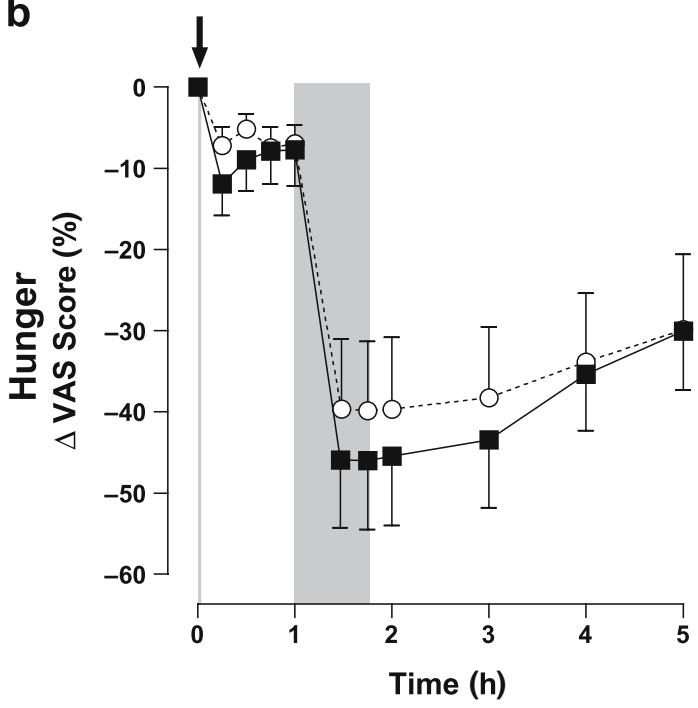

d
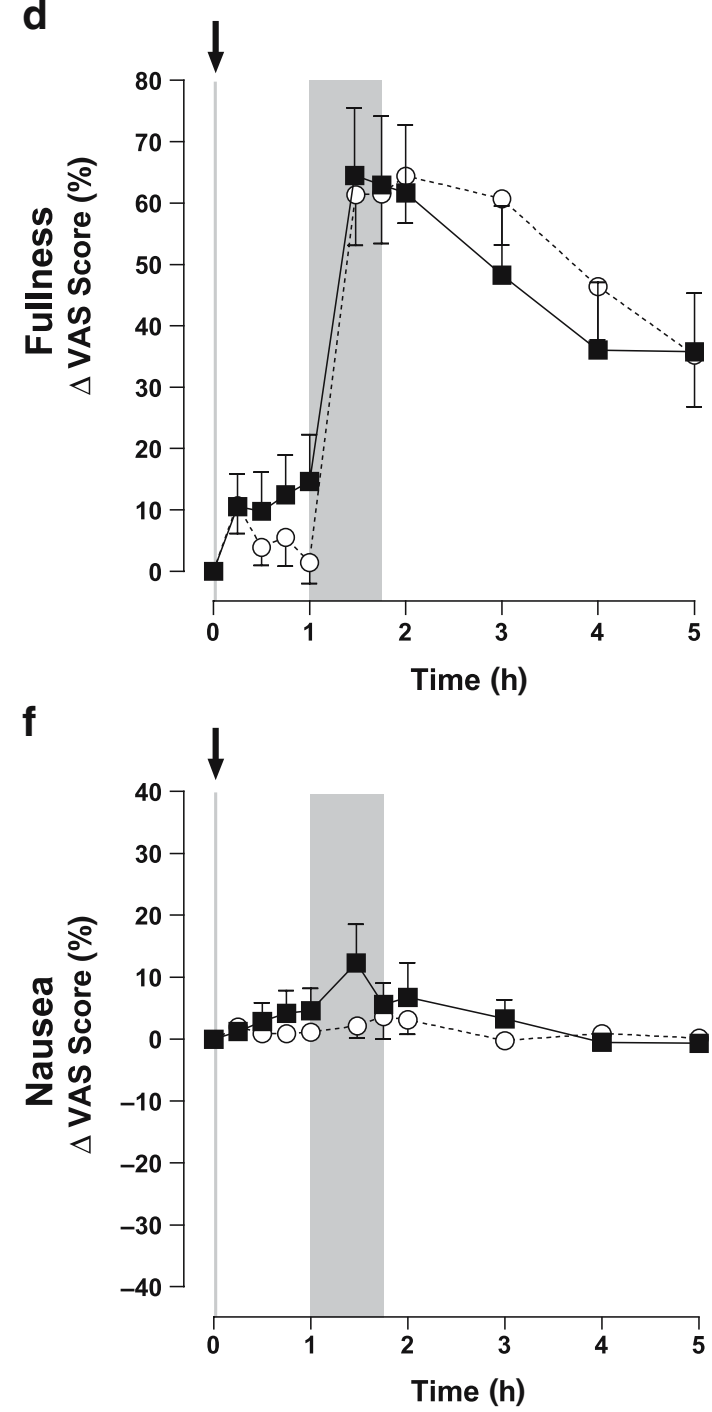

(a, c, e) and 15 obese non-diabetic subjects (b, d, f) (outliers removed). The arrow/grey line indicates injection of either placebo or pramlintide and liquid pre-load meal; the shaded area indicates the time during which the buffet meal was offered 
Fullness In both groups, and on both occasions, mean incremental fullness ratings increased slightly in response to the preload meal $(0-1 \mathrm{~h})$, increased markedly in response to the buffet meal $(1-1.75 \mathrm{~h})$, and then gradually reverted towards baseline values during the postprandial period (1.75-5 h) (Fig. 2c, d).

In both groups, the increases in fullness ratings in response to the preload meal tended to be more marked following pramlintide than following placebo injection, although the differences in the incremental $\mathrm{AUC}_{0-1} \mathrm{~h}$ did not reach statistical significance (Fig. 2c, d).

The increase in fullness ratings in response to the buffet meal, as well as the decline in fullness rating during the postprandial period, were comparable following placebo and pramlintide injection in the type 2 diabetic and obese non-diabetic groups, despite the fact that total energy intake at the buffet meal was $23 \%$ and $16 \%$ lower respectively, following pramlintide injection (Fig. 2c, d).

Nausea Mean nausea ratings only changed minimally throughout the experiments in both groups, with only marginal, non-significant differences found between pramlintide and placebo (Fig. 2e, f).

Relationship between total energy intake and hunger suppression during and after the buffet meal: prandial and postprandial satiety quotients

In both groups, there was a positive and significant relationship between total energy intake at the buffet meal, and the concomitant pre- vs post-meal change in VAS hunger ratings (for the type 2 diabetic group $r=0.50, p=0.02$; for the obese non-diabetic group $r=0.43, p=0.02$ ) (Fig. 3a). That is, the degree of hunger suppression at the buffet meal increased in proportion to the total amount of energy consumed.

In both groups, the regression line for the relationship between total energy intake and hunger suppression at the buffet meal was shifted downward following pramlintide compared with that calculated following placebo injection (Fig. 3a, b). Consequently, following pramlintide injection, a lower total energy intake was needed to achieve the same degree of hunger suppression, as indicated by the vertical lines in Fig. 3a and b (predicting that an $200-\mathrm{kcal}(\sim 836$ $\mathrm{kJ})$ lower total energy intake is needed to achieve $30 \%$ hunger suppression).

Consistent with these correlation analyses, the LS mean prandial satiety quotient, an integrated measure of energy intake and hunger suppression during a given meal, was increased following pramlintide compared with that calculated after placebo injection-by $26 \%$ in the type 2 diabetic group $(0.048 \pm 0.008$ vs $0.038 \pm 0.008, p=0.207)$ and by $58 \%$ in the obese non-diabetic group $(0.041 \pm 0.006$ vs. $0.026 \pm 0.006, p=0.034$ ) (Fig. 3c, d).

The LS mean postprandial satiety quotient, an integrated measure of energy intake and the return of hunger after a given meal, was also increased following pramlintide compared with that calculated following placebo injection-by $100 \%$ in the type 2 diabetic group $(0.038 \pm 0.005$ vs 0.019 $\pm 0.006, p=0.029)$ and by $120 \%$ in the obese non-diabetic group $(0.022 \pm 0.005$ vs $0.01 \pm 0.005, p=0.069)$ (Fig. 3e, f).

Postprandial hormonal analytes and triglyceride excursions

In both groups, following placebo injection, mean incremental plasma concentrations of CCK, total GLP-1, active GLP-1 and total PYY increased slightly in response to the preload meal $(0-1 \mathrm{~h})$, increased markedly in response to the buffet meal $(1-1.75 \mathrm{~h})$, and then gradually returned towards baseline values during the postprandial period $(1.75-5 \mathrm{~h})$ (Fig. 4a-h).

CCK In the type 2 diabetic group, the CCK response to the preload meal was attenuated following pramlintide injection compared with that observed following placebo, as indicated by a significant $58 \%$ reduction in the incremental $\mathrm{AUC}_{0-1 \mathrm{~h}}\left(1.3 \pm 0.4\right.$ vs $\left.3.1 \pm 0.6 \mathrm{pmol} \cdot \mathrm{h}^{-1} \cdot \mathrm{l}^{-1}, p<0.03\right)$. A similar trend was observed in the obese non-diabetic group, although the difference in the $\mathrm{AUC}_{0-1 \mathrm{~h}}$ between pramlintide and placebo was not significant $(2.4 \pm 0.7$ vs $3.0 \pm 0.6$ $\left.\mathrm{pmol} \cdot \mathrm{h}^{-1} \cdot \mathrm{l}^{-1}, p=0.34\right)$. In both groups, the CCK response to the buffet meal was not different between pramlintide and placebo (Fig. 4a, b).

GLP-1 (total and active) As shown by the $>100 \%$ reductions in the incremental $\mathrm{AUC}_{0-1} \mathrm{~h}$, the total GLP-1 response to the preload meal was attenuated following pramlintide injection compared with that observed following placebo in both the type 2 diabetic group $(-1.8 \pm 0.9$ vs $\left.1.9 \pm 0.9 \mathrm{pmol} \cdot \mathrm{h}^{-1} \cdot \mathrm{l}^{-1}, p<0.02\right)$ and the obese non-diabetic group $(-0.3 \pm 0.6$ vs $2.0 \pm 0.8, p<0.04)$. In both groups, the active GLP-1 responses to the preload and buffet meals were similar for pramlintide and placebo (Fig. 4e, f).

PYY (total) In the type 2 diabetic and obese non-diabetic groups, the total PYY responses to the preload meal tended to be lower following pramlintide injection compared with those observed following placebo injection, although the differences in $\mathrm{AUC}_{0-1} \mathrm{~h}$ were not statistically significant (Fig. 4g, h). The total PYY responses to the buffet meal $\left(\mathrm{AUC}_{1-5} \mathrm{~h}\right)$ were also lower following pramlintide injection in both groups, although the difference in $\mathrm{AUC}_{0-5} \mathrm{~h}$ between pramlintide and placebo only reached statistical significance in the type 2 diabetic group $(p<0.05)$.

Triglycerides In both groups, following placebo injection, mean incremental serum triglyceride concentrations gradually and progressively increased in response to the pre-load and buffet meals, and were observed to be still rising at the end of the experiment ( $t=5$ h) (Fig. 5a, b).

The triglyceride response during the $5 \mathrm{~h}$ experiment was attenuated following pramlintide injection compared with that observed following placebo, with reductions in the incremental $\mathrm{AUC}_{0-5 \mathrm{~h}}$ of $36 \%$ observed in the type 2 diabetic $\left(0 \pm 0.7\right.$ vs $\left.3.2 \pm 0.8 \mathrm{mmol} \cdot \mathrm{h}^{-1} \cdot \mathrm{l}^{-1}, p<0.01\right)$ and $34 \%$ in 


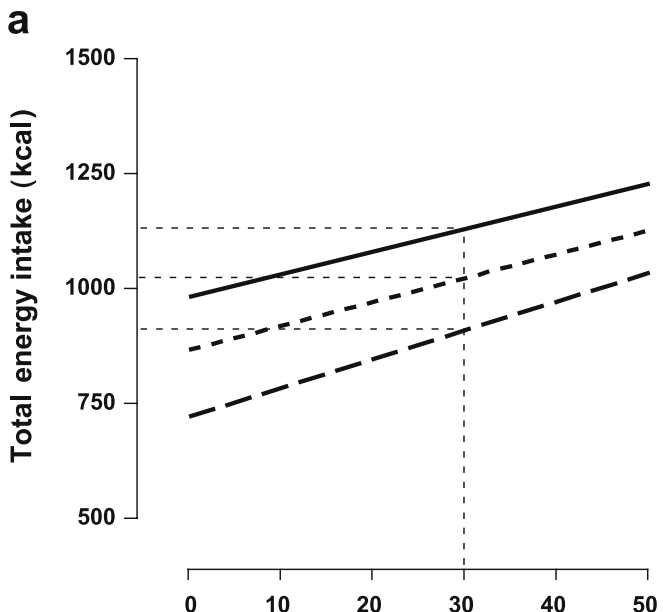

Hunger suppression (\%)

C
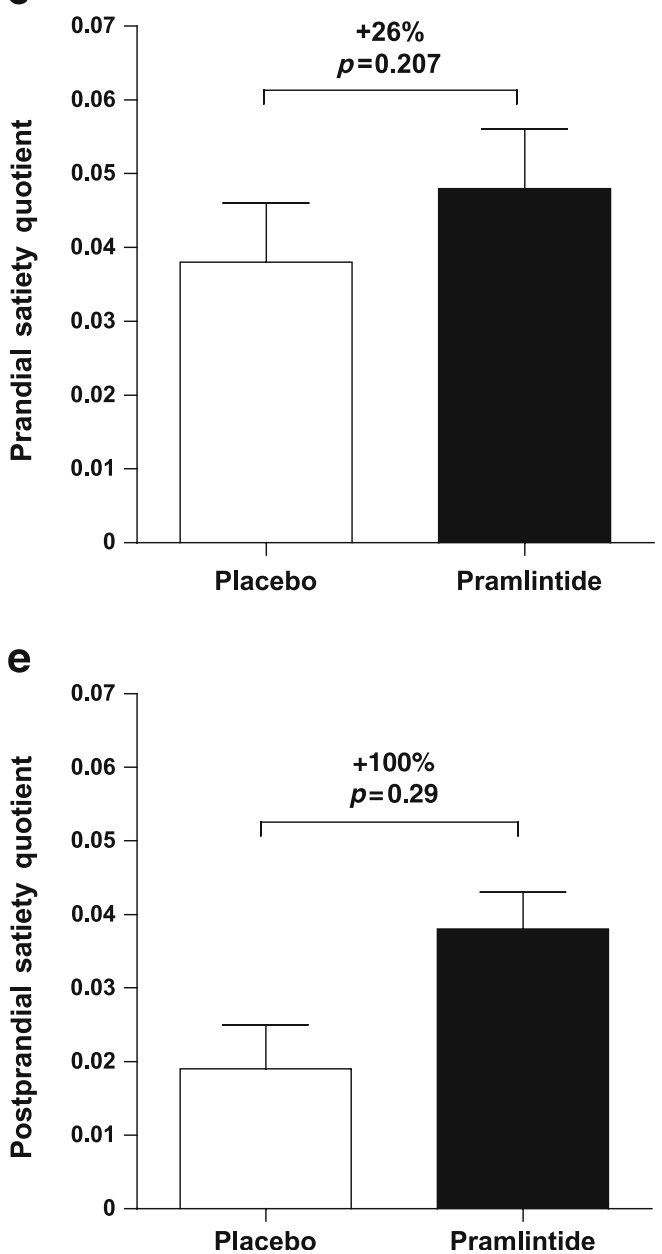

Fig. 3 Relationship between total energy intake and hunger suppression at the buffet meal: satiety quotients. a, b Regression lines for the relationship between total energy intake and hunger suppression (pre- minus post-buffet VAS hunger ratings) (outliers removed). Type 2 diabetes subjects (a): placebo-treated (solid line) $y=636.8+6.4 x$, pramlintide-treated (dashed line) $y=400.8+8.4 x$, combined (dotted line ) $y=502.8+7.9 x ; r=0.50, p=0.02$. Obese non-diabetic subjects (b): placebo-treated (solid line) $y=981.1+4.9 x$, pramlintide-treated (dashed b

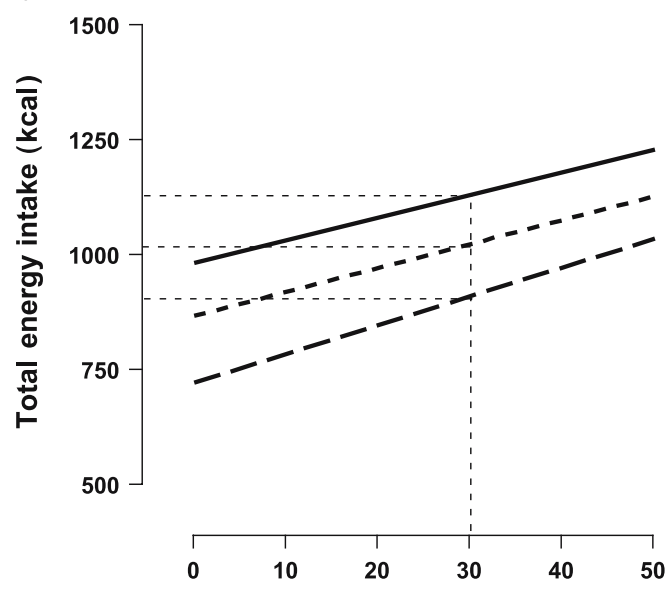

Hunger suppression (\%)

d

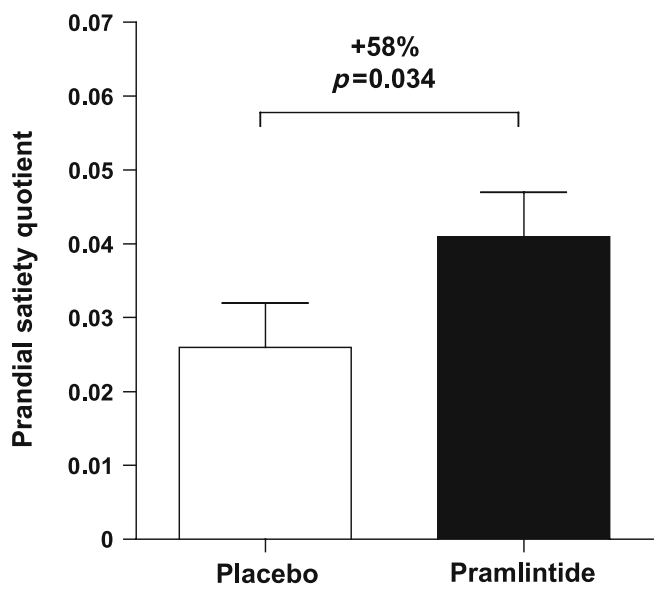

f

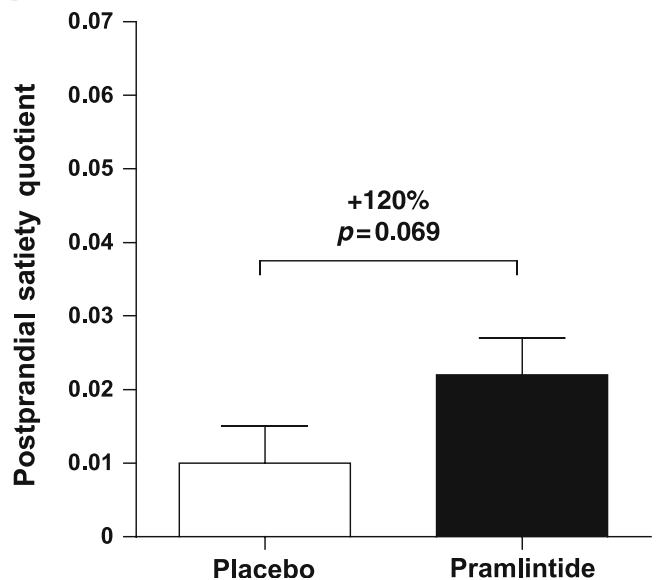

line) $y=720.6+6.3 x$, combined (dotted line) $y=866.4+5.2 x ; r=0.43$, $p=0.02$. c-f LS mean $( \pm$ SEM) satiety quotients. Prandial satiety quotients (pre- minus post-buffet VAS hunger ratings/total energy intake) $(\mathbf{c}, \mathbf{d})$ and postprandial satiety quotients $(5 \mathrm{~h}$ minus individual end of buffet VAS hunger ratings/total energy intake) (e, f) following a single s.c. injection of placebo or $120 \mu \mathrm{g}$ of pramlintide in 11 subjects with insulin-treated type 2 diabetes (c,e) and 15 obese non-diabetic subjects (d, f). kilocalorie to kiloJoule conversion: $1 \mathrm{kcal}=4.18 \mathrm{~kJ}$ 
Fig. 4 Mean $( \pm$ SEM) incremental changes in plasma concentrations of CCK $(\mathbf{a}, \mathbf{b})$, total GLP-1 (c, d), active GLP-1 (e, f), and total PYY $(\mathbf{g}, \mathbf{h})$ following a single s.c. injection of placebo (open circles, dotted lines) or 120 $\mu \mathrm{g}$ of pramlintide (filled squares, solid lines) in 11 subjects with insulin-treated type 2 diabetes $(\mathbf{a}, \mathbf{c}, \mathbf{e}, \mathbf{g})$ and 15 obese nondiabetic subjects $(\mathbf{b}, \mathbf{d}, \mathbf{f}, \mathbf{h})$. The arrow/grey line indicates injection of either placebo or pramlintide and ingestion of the liquid pre-load meal; the shaded area indicates the time during which the buffet meal was offered a

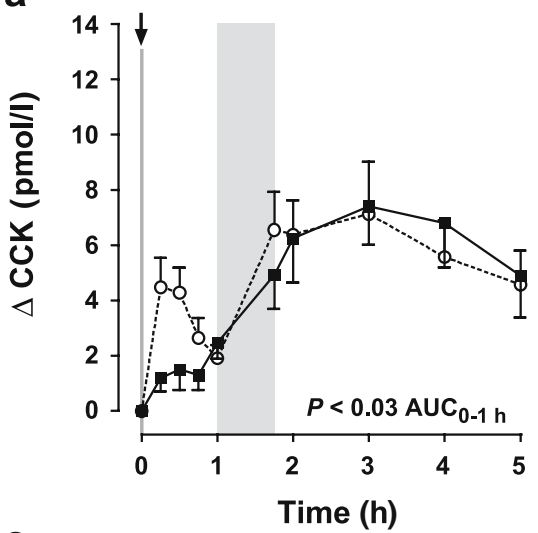

C

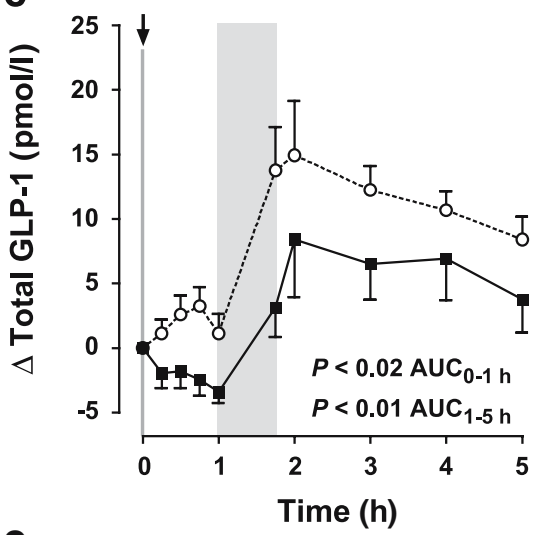

e

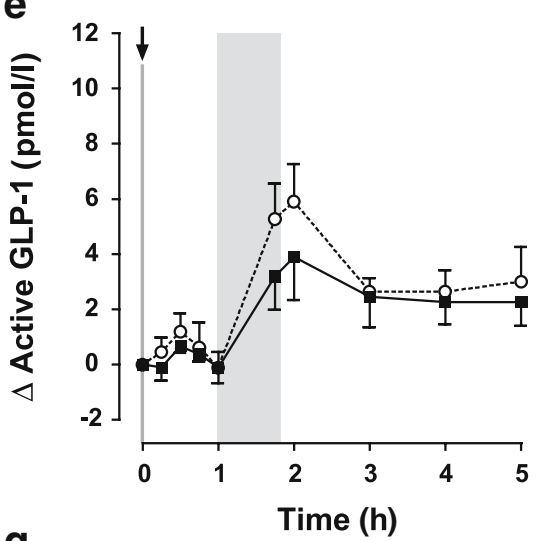

g

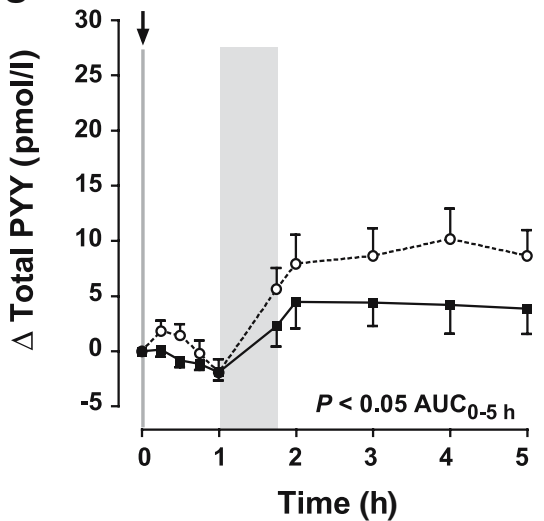

b

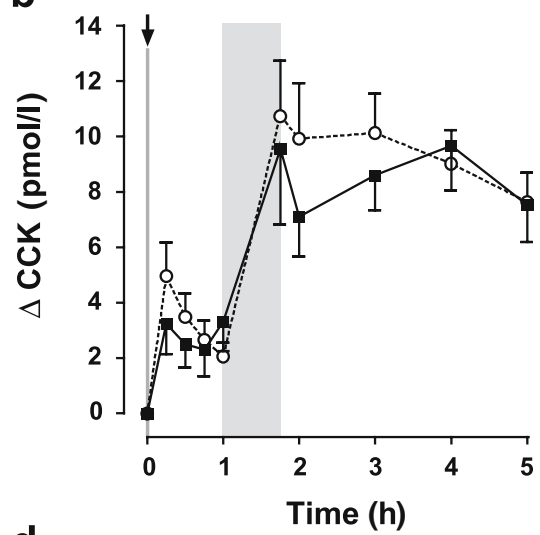

d
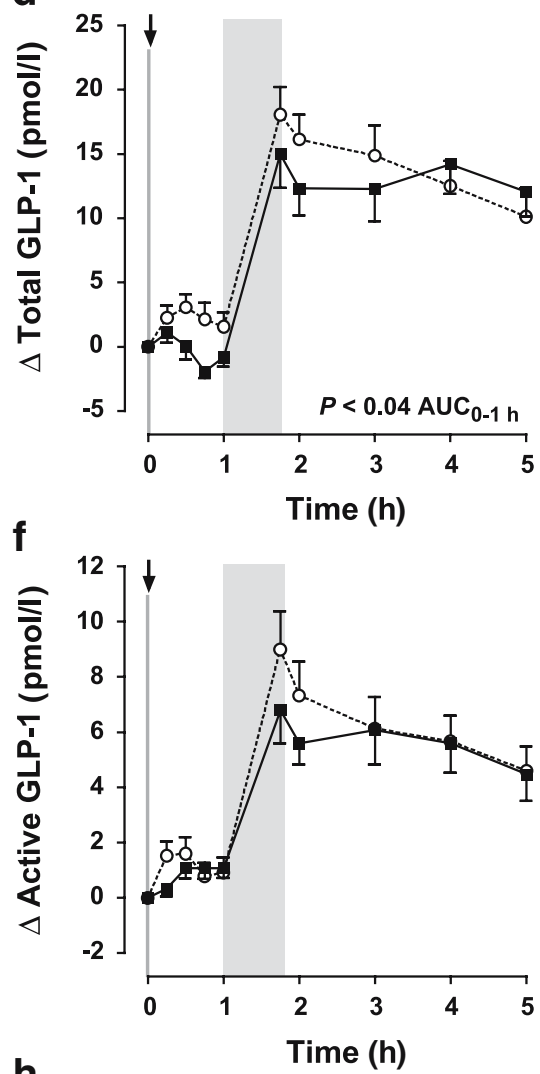

h

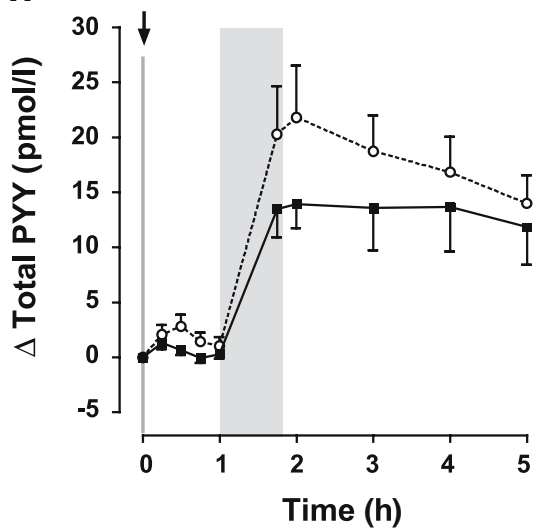


Fig. 5 Mean $( \pm$ SEM) incremental changes in plasma triglyceride concentrations following a single s.c. injection of placebo (open circles, dotted lines) or 120 $\mu \mathrm{g}$ pramlintide (filled squares, solid lines) in 11 subjects with insulin-treated type 2 diabetes (a) and 15 obese non-diabetic subjects (b). The arrow/grey line indicates injection of either placebo or pramlintide and liquid pre-load meal; the shaded area indicates the time during which the buffet meal was offered
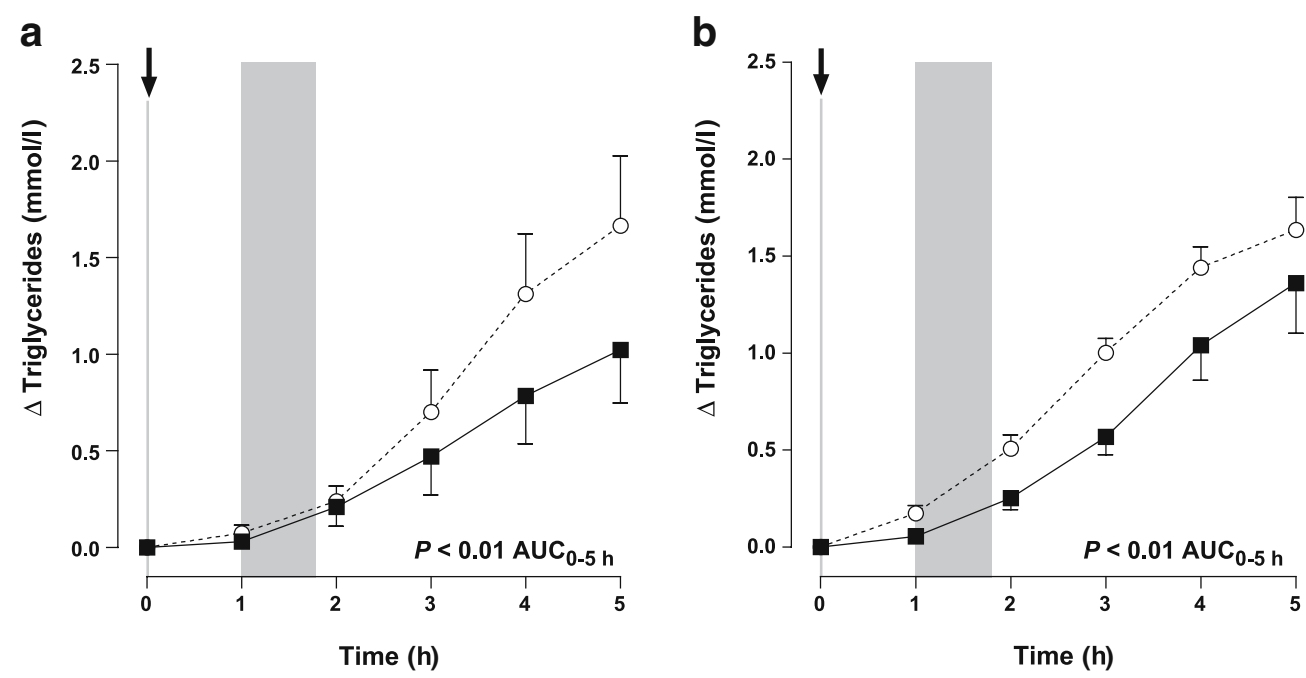

the obese non-diabetic $\left(2.6 \pm 0.4\right.$ vs $3.9 \pm 0.3 \mathrm{mmol} \cdot \mathrm{h}^{-1} \cdot \mathrm{l}^{-1}$, $p<0.01)$ groups.

\section{Safety}

Pramlintide was generally well tolerated, with no serious adverse events occurring. In the type 2 diabetic group, one subject on pramlintide reported mild anorexia and nausea ( $\sim 7 \mathrm{~h}$ after dosing), and one subject on placebo reported reduced appetite. None of the subjects in the obese nondiabetic group reported adverse events whilst on pramlintide, whereas three subjects reported a total of six mild adverse events on placebo (two reports of headache, and one report each of fatigue, diarrhoea, nausea and vomiting).

\section{Discussion}

Several randomised, double-blind, placebo-controlled longterm trials on patients with type 2 diabetes have shown that the addition of pramlintide to pre-existing insulin regimens led to a further improvement in glycaemic control that was consistently accompanied by weight loss $[34,35]$. In recent pooled analyses of two long-term type 2 diabetes studies, 26 weeks of treatment with pramlintide $(120 \mu \mathrm{g}$ twice daily $)$ led to a significant, placebo-corrected reduction in body weight that was progressive in nature, evident in subjects who did not report nausea, and most pronounced in subjects who were severely obese at baseline (averaging $\sim 3 \mathrm{~kg}$ in subjects with an entry BMI of $>35 \mathrm{~kg} / \mathrm{m}^{2}$ ) [36].

The results of the present study provide evidence that pramlintide exerts a satiating effect in humans, and that reduced food intake may be a mechanism for the weight loss observed in overweight subjects in long-term clinical diabetes trials with this compound.

Compared with placebo, a single s. c. injection of pramlintide given $1 \mathrm{~h}$ prior to an ad libitum buffet meal resulted in a significant reduction in total energy intake that averaged $202 \mathrm{kcal}(844 \mathrm{~kJ}, \sim 23 \%)$ in insulin-treated type 2 diabetic subjects and $170 \mathrm{kcal}(711 \mathrm{~kJ}, \sim 16 \%)$ in obese nondiabetic subjects. Although differences in study design preclude the direct comparison of our results with those obtained with other peptide hormones, it is noteworthy that the magnitude of the reduction in food intake observed in response to pramlintide is similar to that reported for other gastrointestinal satiety signals, such as GLP-1 [9-11], PYY $[13,14]$ and CCK $[1-5,7,8]$. In most of the aforementioned studies, peptides were administered via continuous i.v. infusion. In contrast, in the present study, pramlintide was administered as a single preprandial $120-\mu$ g injection, consistent with the method of administration used in previous long-term trials. Considering that the average daily energy intake of US adults over the past 30 years has increased by an estimated 7\% (168 kcal) in males and 22\% $(335 \mathrm{kcal})$ in females, as reported in recent NHANES-based CDC estimates [46], and that an $\sim 20 \%$ reduction in adlibitum food intake, if maintained, could translate into a substantial energy deficit over weeks and months, our findings are of considerable clinical relevance.

The reductions in total energy intake induced by pramlintide (compared with placebo) were attributable to proportional reductions in energy derived from fat, carbohydrate and protein, suggesting that pramlintide had no major effect on macronutrient preference. However, this finding should be interpreted with caution, given that most of the food items offered at the ad libitum buffet meal were of mixed macronutrient composition, with relatively few high-fat and high-carbohydrate choices that might have been required to detect a putative drug effect.

The finding that pramlintide did not affect mean meal duration, despite its effect on total energy intake, should also be interpreted with caution. In a rodent study by Lutz et al. [46], peripheral amylin administration reduced meal duration and meal size, leading the authors to suggest that amylin may be an important physiological mediator of meal termination. Given that the plasma concentration of pramlintide peaks at 20-30 min after s.c. injection [28], it is possible that meal duration would be reduced if pramlintide 
were injected within $15 \mathrm{~min}$, rather than $1 \mathrm{~h}$, prior to an ad libitum meal.

Analyses of the VAS data reveal interesting insights into the potential mechanisms underlying the observed reduction in food intake with pramlintide. The preload/buffet meal setting used in the present study was highly informative in this regard, allowing us to assess the effect of pramlintide on hunger, fullness and nausea ratings in the context of both standardised (fixed energy) and ad libitum unrestricted energy meals. The VAS ratings during the first hour after injection suggest that enhanced pre-prandial fullness may have been one contributor to the observed reduction in energy intake with pramlintide, a possibility that could be formally tested in a larger study. Over the period during which the buffet meal was available, subjective ratings of hunger decreased and those of fullness increased to a similar extent with pramlintide and placebo, despite the fact that the mean total energy intake was $~ 20 \%$ lower following pramlintide than that following placebo injection. The finding that less food needed to be consumed to elicit comparable hunger suppression and fullness induction during the meal, and a comparable return of hunger and dissipation of fullness after the meal, suggests that pramlintide enhances the satiating effect of meals during both the prandial and postprandial period. This notion is further supported by our correlation analyses, and the finding that the prandial and postprandial satiety quotients [41] were both increased following pramlintide injection. Compared with the fullness and hunger ratings, mean nausea ratings remained essentially unchanged throughout the two study periods. This observation, and the fact that none of the subjects in the type 2 diabetic and obese non-diabetic groups reported nausea as an adverse event within the $5 \mathrm{~h}$ study period after the administration of pramlintide, clearly excludes nausea as the primary explanation for reduced food intake.

To examine whether the effect of pramlintide on food intake may, at least in part, be mediated via effects on other humoral mediators of satiety, including gastrointestinal peptide hormones and/or postprandial lipaemia, we measured the postprandial profiles of plasma CCK, GLP-1 (total and active), total PYY and serum triglycerides. The results indicate that none of these factors appear to account for the observed satiating effect of pramlintide. The responses of CCK, total GLP-1 and total PYY to the pre-load meal, and the overall postprandial triglyceride excursions were attenuated rather than augmented following pramlintide administration. The mechanism(s) underlying the attenuation of the CCK, total GLP-1 and total PYY responses to the pre-load meal with pramlintide remains to be elucidated. The reduced responses may reflect, at least in part, slower gastric emptying of the preload meal [18], thereby decreasing small intestinal nutrient stimulation. However, if this were the dominant mechanism, a diminished response to the buffet meal (which was smaller after pramlintide treatment) would be expected, but this was only evident for PYY (and then only in the tpe 2 diabetic group). A more likely explanation is that pramlintide inhibits vagal efferents that modulate CCK, GLP-1 and PYY release during the early postprandial period. This concept is supported by the fact that the early postprandial secretion of CCK, GLP-1 and PYY is under vagal control [47], and non-clinical [18] and clinical [32] evidence that the effect of amylin/pramlintide on gastric emptying is also vagally mediated. Of note, in rodents with bilateral vagotomy, the effect of amylin on food intake is preserved, while the effect on gastric emptying is abolished, indicating that the anorexigenic effect of amylin is, at least partly, dissociated from its effect on gastrointestinal motility [48].

Slowed gastric emptying, together with reduced fat intake at the buffet meal, may have contributed, however, to the observed reduction in postprandial triglyceride excursions following pramlintide injection. The latter finding is consistent with previous results in type 1 diabetic patients and is of potential clinical significance given that postprandial hypertriglyceridaemia is increasingly recognised as being an important cardiovascular risk factor [49].

In summary, a single s. c. injection of pramlintide (120 $\mu \mathrm{g}$ ) given $1 \mathrm{~h}$ prior to a buffet meal significantly reduced ad libitum food intake in subjects with insulin-treated type 2 diabetes and in obese non-diabetic subjects. The VAS results indicate that the reduction in food intake is clearly dissociated from the perception of nausea, and is more likely due to an enhancement of the satiating effect of food. These findings are consistent with the well-characterised anorexigenic effect of amylin in rodents, and suggest that reduced food intake may be a mechanism for the weight loss that has been consistently observed in long-term trials with pramlintide in overweight patients with diabetes.

Acknowledgements We are indebted to S. Skare, D. Deckhut, S. McIntyre, S. Hahs and M. Sierzega for their excellent assistance in conducting, reporting and the quality control of the study, and to $\mathrm{M}$. Weyer for assistance with the graphs.

\section{References}

1. Druce M, Bloom SR (2003) Central regulators of food intake. Curr Opin Clin Nutr Metab Care 6:361-367

2. Wynne K, Stanley S, Bloom S (2004) The gut and regulation of body weight. J Clin Endocrinol Metab 89:2576-2582

3. Druce MR, Small CJ, Bloom SR (2004) Minireview: gut peptides regulating satiety. Endocrinology 145:2660-2665

4. Stanley S, Wynne K, Bloom S (2004) Gastrointestinal satiety signals: III. Glucagon-like peptide 1, oxyntomodulin, peptide YY, and pancreatic polypeptide. Am J Physiol Gastrointest Liver Physiol 286:G693-G697

5. Halford JC, Cooper GD, Dovey TM (2004) The pharmacology of human appetite expression. Curr Drug Targets 5:221-240

6. Wren AM, Seal LJ, Cohen MA et al (2001) Ghrelin enhances appetite and increases food intake in humans. J Clin Endocrinol Metab 86:5992

7. Pi-Sunyer X, Kissileff HR, Thornton J, Smith GP (1982) C-terminal octapeptide of cholecystokinin decreases food intake in obese men. Physiol Behav 29:627-630

8. Rayner CK, Park HS, Doran SM, Chapman IM, Horowitz M (2000) Effects of cholecystokinin on appetite and pyloric motility during physiological hyperglycemia. Am J Physiol Gastrointest Liver Physiol 278:G98-G104 
9. Gutzwiller JP, Drewe J, Goke B et al (1999) Glucagon-like peptide-1 promotes satiety and reduces food intake in patients with diabetes mellitus type 2. Am J Physiol 276:R1541-R1544

10. Naslund E, Barkeling B, King N et al (1999) Energy intake and appetite are suppressed by glucagon-like peptide-1 (GLP-1) in obese men. Int J Obes 23:304-311

11. Flint A, Raben A, Astrup A, Holst JJ (1998) Glucagon-like peptide 1 promotes satiety and suppresses energy intake in humans. J Clin Invest 101:515-520

12. Cohen MA, Ellis SM, Le Roux CW et al (2003) Oxyntomodulin suppresses appetite and reduces food intake in humans. J Clin Endocrinol Metab 88:4696-4701

13. Batterham RL, Cowley MA, Small CJ et al (2002) Gut hormone PYY(3-36) physiologically inhibits food intake. Nature 418: 650-654

14. Batterham RL, Cohen MA, Ellis SM et al (2003) Inhibition of food intake in obese subjects by peptide YY3-36. N Engl J Med 349:941-948

15. Geary N, Kissileff HR, Pi-Sunyer FX, Hinton V. (1992) Individual, but not simultaneous, glucagon and cholecystokinin infusions inhibit feeding in men. Am J Physiol 262:R975-R980

16. Batterham RL, Le Roux CW, Cohen MA et al (2003) Pancreatic polypeptide reduces appetite and food intake in humans. J Clin Endocrinol Metab 88:3989-3992

17. Lieverse RJ, Jansen JB, Masclee AM, Lamers CB (1995) Effects of somatostatin on human satiety. Neuroendocrinology 61:112116

18. Young AA (1997) Amylin's physiology and its role in diabetes. Curr Opin Endocrinol Diabetes 4:282-290

19. Beaumont K, Kenney MA, Young AA, Rink TJ (1993) High affinity amylin binding sites in rat brain. Mol Pharmacol 44:493497

20. Sexton PM, Paxinos G, Kenney MA, Wookey PJ, Beaumont K (1994) In vitro autoradiographic localization of amylin binding sites in rat brain. Neuroscience 62:553-567

21. Muff R, Buhlmann N, Fischer JA, Born W (1999) An amylin receptor is revealed following co-transfection of a calcitonin receptor with receptor activity modifying proteins-1 or -3 . Endocrinology 140:2924-2927

22. Rushing PA, Hagan MM, Seeley RJ, Lutz TA, Woods SC (2000) Amylin: a novel action in the brain to reduce body weight. Endocrinology 141:850-853

23. Lutz TA, Mollet A, Rushing PA, Riediger T, Scharrer E (2001) The anorectic effect of a chronic peripheral infusion of amylin is abolished in area postrema/nucleus of the solitary tract (AP/ NTS) lesioned rats. Int J Obes Relat Metab Disord 25:10051011

24. Rushing PA, Lutz TA, Seeley RJ, Woods SC (2000) Amylin and insulin interact to reduce food intake in rats. Horm Metab Res 32:62-66

25. Mack C, Hoyt J, Moore C, Jodka C, Sams-Dodd F (2003) Sustained reduction in food intake and body weight in high fatfed rats during 28-day amylin infusion. Diabetes 52[Suppl 1]: A389 (Abstract 1690-P)

26. Rushing PA, Hagan MM, Seeley RJ et al (2001) Inhibition of central amylin signaling increases food intake and body adiposity in rats. Endocrinology 142:5035-5038

27. Reidelberger RD, Haver AC, Arnelo U, Smith DD, Schaffert CS, Permert J (2004) Amylin receptor blockade stimulates food intake in rats. Am J Physiol 287:R568-R574

28. Weyer C, Maggs DG, Young AA, Kolterman OG (2001) Amylin replacement with pramlintide as an adjunct to insulin therapy in type 1 and type 2 diabetes mellitus: a physiological approach toward improved metabolic control. Curr Pharm Des 7:13531373

29. Edelman SV, Weyer C (2002) Unresolved challenges with insulin therapy in type 1 and type 2 diabetes: potential benefit of replacing amylin, a second $\beta$-cell hormone. Diabetes Technol Ther 4:175-189
30. Maggs DG, Fineman MS, Kornstein J et al (2004) Pramlintide reduces postprandial glucose excursions when added to insulin lispro in subjects with type 2 diabetes: a dose timing study. Diabetes Metab Res Rev 20:55-60

31. Fineman M, Weyer C, Maggs DG, Strobel S, Kolterman OG (2002) The human amylin analog, pramlintide, reduces postprandial hyperglucagonemia in patients with type 2 diabetes mellitus. Horm Metab Res 34:504-508

32. Vella A, Lee JS, Camilleri M et al (2002) Effects of pramlintide, an amylin analogue, on gastric emptying in type 1 and 2 diabetes mellitus. Neurogastroenterol Motil 14:123-131

33. Whitehouse FW, Kruger D, Fineman MS et al (2002) A randomized study and open label extension evaluating the long-term efficacy of pramlintide as an adjunct to insulin therapy in type 1 diabetes. Diabetes Care 25:724-730

34. Ratner RE, Want LL, Fineman MS et al (2002) Adjunctive therapy with the amylin analogue pramlintide leads to a combined improvement in glycemic and weight control in insulin-treated patients with type 2 diabetes. Diabetes Technol Ther 4:51-61

35. Hollander PA, Levy P, Fineman MS et al (2003) Pramlintide as an adjunct to insulin therapy improves long-term glycemic and weight control in patients with type 2 diabetes mellitus: a one year randomized controlled trial. Diabetes Care 26:784-790

36. Hollander P, Fineman MS, Ruggles JA et al (2004) Effect of pramlintide on weight in overweight and obese insulin-treated type 2 diabetes patients. Obes Res 12:661-668

37. Martini MC, Lampe JW, Slavin JL, Kurzer MS (1994) Effect of the menstrual cycle on energy and nutrient intake. Am J Clin Nutr 60:895-899

38. Stunkard AJ, Messick S (1985) The three-factor eating questionnaire to measure dietary restraint, disinhibition and hunger. J Psychosom Res 29:71-83

39. World Health Organization (1995) Physical status: the use and interpretation of anthropometry. Report of a WHO Expert Committee. WHO Technical Report Series, 854. World Health Organization, Geneva

40. Sepple CP, Read NW (1989) Gastrointestinal correlates of the development of hunger in man. Appetite 13:183-191

41. Green SM, Delargy HJ, Joanes D, Blundell JE (1997) A satiety quotient: a formulation to assess the satiating effect of food. Appetite 29:291-304

42. Santangelo A, Peracchi M, Conte D, Fraquelli M, Porrini M (1998) Physical state of meal affects gastric emptying, cholecystokinin release and satiety. Br J Nutr 80:521-527

43. MacIntosh CG, Morley JE, Wishart J et al (2001) Effect of exogenous cholecystokinin (CCK)-8 on food intake and plasma CCK, leptin, and insulin concentrations in older and young adults: evidence for increased CCK activity as a cause of the anorexia of aging. J Clin Endocrinol Metab 86:5830-5837

44. Linco Research. Available at: http://www.lincoresearch.com, last accessed in October 2004

45. Centers for Disease Control and Prevention (2004) Trends in intake of energy and macronutrients-United States, 19712000. MMWR Morb Mortal Wkly Rep 53:80-82

46. Lutz TA, Geary N, Szabady MM, Del Prete E, Scharrer E (1995) Amylin decreases meal size in rats. Physiol Behav 58:11971202

47. Rocca AS, Brubaker PL (1999) Role of the vagus nerve in mediating proximal nutrient-induced glucagon-like peptide-1 secretion. Endocrinology 140:1687-1694

48. Lutz TA, Del Prete E, Scharrer E (1995) Subdiaphragmatic vagotomy does not influence the anorectic effect of amylin. Peptides 16:457-462

49. Levetan C, Want L, Weyer C et al (2003) Impact of pramlintide on glucose fluctuations and postprandial glucose, glucagons and triglyceride excursions among patients with type 1 diabetes intensively treated with insulin pumps. Diabetes Care 26:1-8 